\title{
The Relation between Serum Uric Acid and HbA1c Is Dependent upon Hyperinsulinemia in Patients with Newly Diagnosed Type 2 Diabetes Mellitus
}

\author{
Yuliang Cui, Hemei Bu, Xianghua Ma, Sha Zhao, Xiaona Li, and Shan Lu \\ Department of Endocrinology, The First Affiliated Hospital of Nanjing Medical University, Nanjing 210029, China \\ Correspondence should be addressed to Xianghua Ma; xianghuama@126.com
}

Received 30 March 2016; Accepted 16 May 2016

Academic Editor: Raffaele Marfella

Copyright (c) 2016 Yuliang Cui et al. This is an open access article distributed under the Creative Commons Attribution License, which permits unrestricted use, distribution, and reproduction in any medium, provided the original work is properly cited.

Objective. The aim of our study was to explore the dependent condition of the relationship between uric acid and blood glucose in type 2 diabetes. Research Design and Methods. We measured the HbAlc, serum uric acid, creatinine, lipids profiles, and so forth of 605 newly diagnosed type 2 diabetes patients, and oral glucose tolerance tests (OGTTs) were performed on each patient. The population was divided into high and low insulin groups. Multiple linear regression analyses were conducted to assess the relationship between uric acid and HbAlc. Results. Serum uric acid and HbAlc levels were low in newly diagnosed type 2 diabetes patients. However, we found no significant relationship between uric acid and HbAlc by regression analysis after adjusting total insulin. The concentration of uric acid was inversely correlated with HbAlc in the high insulin group, regardless of patient sex. However, no associations were found in low insulin group. Conclusions. The negative correlation between uric acid and HbAlc is conditional in newly diagnosed type 2 diabetes patients and is related to hyperinsulinemia. Therefore, uric acid is likely only useful as a biomarker of blood glucose in patients exhibiting hyperinsulinemia.

\section{Introduction}

Type 2 diabetes mellitus is one of the most common and disabling metabolic diseases; its increasing incidence has become a serious threat to human health [1]. Increasing evidence suggests that hyperuricemia is an independent risk factor for impaired fasting glucose (IFG) and type 2 diabetes. Patients with hyperuricemia are at a significantly higher risk of progressing to type 2 diabetes $[2,3]$. A large number of researchers have begun to consider uric acid as a serum indicator of glycometabolic disorders, because of a correlation between uric acid and glucose metabolism $[4,5]$. However, changes in serum uric acid and blood glucose do not exhibit a linear relationship, as some have assumed. Rather, the relationship follows more of a bell curve. Uric acid levels rise with increasing blood glucose concentrations in the normal and prediabetes population. However, in type 2 diabetes patients, uric acid levels tend to decline with increasing blood glucose concentrations $[6,7]$.
The reasons for the inverse relationship between uric acid and blood glucose in type 2 diabetes mellitus remain unclear. However, insulin levels are also closely related to uric acid levels. Serum uric acid levels will increase with increasing serum insulin levels in diabetic patients $[8,9]$. Whether insulin is the factor that influences the relationship between the uric acid and blood glucose is not clear. Previous studies did not provide an explanation. Thus, our study aimed to further explore the connection between uric acid and blood glucose in newly diagnosed type 2 diabetes.

\section{Research Design and Methods}

2.1. Study Population. We performed a retrospective analysis on the inpatient database in the First Affiliated Hospital of Nanjing Medical University (China) between 2008 and 2014. We chose 605 individuals ( 435 males and 170 females) aged 30-74-years with newly diagnosed type 2 diabetes. The 
diagnosis for type 2 diabetes was in accordance with the diagnostic criteria promulgated by the World Health Organization (WHO) in 1990. Screening criteria were as follows: (1) patients must have newly diagnosed type 2 diabetes and have never received hypoglycemic drugs, diet, or exercise therapy prior to admission to the hospital. (2) Patients must have never received any drugs that would affect blood glucose, insulin, or serum uric acid before testing. (3) Patients must have no history of serious liver or kidney problems or infection, trauma, or stress. All patients were admitted to our hospital to screen for diabetic complications and to evaluate islet-beta cell function after they were diagnosed with type 2 diabetes (FBG $\geqq 7.0$ or PBG $\geqq 11.1$ ) in the outpatient department. There was no stress hyperglycemia or transient hyperglycemia caused by other reasons. There were 800 cases that were evaluated. Among them, 58 patients were excluded because they had taken drugs affecting uric acid, while 89 cases were excluded because they had impaired liver or kidney functions and 48 were not included because their data were incomplete.

2.2. Physical Examination and Laboratory Methods. We analyzed the age, history of diabetes, height, weight, systolic blood pressure (SBP), and diastolic blood pressure (DBP) in all the patients. Venous blood samples were collected after fasting for more than 8 hours. The serology indexes, such as triglyceride (TG), creatinine (Cr), and serum uric acid (SUA) levels, were measured by automatic biochemical analyzer. Glycated hemoglobin (HbAlc) was measured by high-performance liquid chromatography (HPLC). The oral glucose tolerance test (OGTT) and insulin release test (IRT) were performed in all patients. Blood samples were collected at fasting $(0 \mathrm{~min})$ and at 30, 60, and 120 minutes after taking $75 \mathrm{~g}$ anhydrous glucose to measure plasma glucose (dextrose oxidase method) and serum insulin (radioimmunoassay).

2.3. Calculations. The body mass index (BMI) was calculated by dividing the weight $(\mathrm{kg})$ by the height $(\mathrm{m})$ squared. Total insulin level was represented as the area under curve of insulin during $0-120 \mathrm{~min}$ of the IRT [10], which was obtained from the irregular trapezoid method (Area = $\left.1 / 2 \sum_{i=1}^{n} X_{i-1}\left(Y_{i-1}+Y_{i}\right)\right)[11]$.

2.4. Statistical Analysis. All statistical analyses were computed using SPSS for Windows, version 17.0. Measurement data were expressed as $\bar{x} \pm s$. All of the comparisons between measurement data in line with the normal distribution were analyzed by independent samples $t$-test. A test of normality was performed for all the arguments, and the variables showing skewed distribution that took natural logarithms were converted to meet the normal distribution. Pearson correlation tests and multivariate linear regression analyses were used to assess the relationship between $\mathrm{HbAlc}$ and InsAUC120, the relationship between serum uric acid and InsAUC120, and the relationship between serum uric acid and HbAlc. The data were divided according to the two types of patient groups: a low insulin group and a high insulin group, based on the median InsAUC120 level in male versus
TABLE 1: Basic/clinical characteristics of study participants by gender and the difference between males and females $(\bar{x} \pm s)$.

\begin{tabular}{|c|c|c|c|c|}
\hline $\begin{array}{l}\text { General } \\
\text { indexes }\end{array}$ & Male $(n=435)$ & Female $(n=170)$ & $t$ & $P$ \\
\hline Age (yr) & $51.22 \pm 12.65$ & $56.14 \pm 9.83$ & -4.561 & $0.000^{*}$ \\
\hline $\begin{array}{l}\text { BMI } \\
\left(\mathrm{kg} / \mathrm{m}^{2}\right)\end{array}$ & $25.91 \pm 3.56$ & $25.18 \pm 3.45$ & 2.262 & $0.024^{*}$ \\
\hline $\begin{array}{l}\text { SBP } \\
(\mathrm{mmHg})\end{array}$ & $134.40 \pm 18.09$ & $131.70 \pm 15.71$ & 1.813 & 0.071 \\
\hline $\begin{array}{l}\text { DBP } \\
(\mathrm{mmHg})\end{array}$ & $84.19 \pm 10.93$ & $82.13 \pm 9.56$ & 2.280 & $0.023^{*}$ \\
\hline HbAlc (\%) & $10.45 \pm 2.24$ & $10.40 \pm 2.36$ & 0.257 & 0.797 \\
\hline $\operatorname{ALT}(\mathrm{U} / \mathrm{L})$ & $35.66 \pm 28.80$ & $31.93 \pm 27.30$ & 1.453 & 0.147 \\
\hline AST (U/L) & $27.23 \pm 18.35$ & $28.45 \pm 21.67$ & -0.696 & 0.478 \\
\hline $\begin{array}{l}\text { TC } \\
(\mathrm{mmol} / \mathrm{L})\end{array}$ & $4.99 \pm 1.68$ & $5.25 \pm 1.10$ & -1.837 & 0.067 \\
\hline $\begin{array}{l}\text { TG } \\
(\mathrm{mmol} / \mathrm{L})\end{array}$ & $2.39 \pm 1.51$ & $1.60 \pm 0.85$ & 3.397 & $0.001^{*}$ \\
\hline $\begin{array}{l}\mathrm{HDL} \\
(\mathrm{mmol} / \mathrm{L})\end{array}$ & $1.10 \pm 0.40$ & $1.26 \pm 0.75$ & -4.117 & $0.000^{*}$ \\
\hline $\begin{array}{l}\mathrm{LDL} \\
(\mathrm{mmol} / \mathrm{L})\end{array}$ & $3.57 \pm 0.82$ & $3.39 \pm 0.34$ & 0.252 & 0.801 \\
\hline $\begin{array}{l}\text { BUN } \\
(\mathrm{mmol} / \mathrm{L})\end{array}$ & $5.68 \pm 2.82$ & $5.01 \pm 1.36$ & 2.932 & $0.003^{*}$ \\
\hline $\mathrm{Cr}(\mu \mathrm{mol} / \mathrm{L})$ & $73.56 \pm 15.93$ & $54.44 \pm 10.04$ & 17.624 & $0.000^{*}$ \\
\hline $\begin{array}{l}\text { SUA } \\
(\mu \mathrm{mol} / \mathrm{L})\end{array}$ & $325.70 \pm 84.28$ & $272.65 \pm 66.74$ & 8.133 & $0.005^{*}$ \\
\hline
\end{tabular}

SBP: systolic pressure, DBP: diastolic pressure, HbAlc: glycosylated hemoglobin, ALT: glutamic-pyruvic transaminase, AST: glutamic oxaloacetic transaminase, TC: total cholesterol, TG: triglycerides, HDL: high density lipoprotein, LDL: low density lipoprotein, BUN: blood urea nitrogen, Cr: creatinine, and SUA: serum uric acid. The $t$-test with different samples was adopted for comparison between groups. ${ }^{*} P<0.05$ was considered as statistically significant difference.

female gender groups [10]. The correction between serum uric acid and HbAlc was evaluated within each group. A $P$ value of $<0.05$ (two-tailed) was considered to be statistically significant.

\section{Results}

In Table 1, the general clinical data gathered for each gender group is presented. Regardless of gender, HbAlc was inversely correlated with InsAUC120 (Figure 1, Table 2). The correlation still existed after adjusting possible influencing factors, such as age, BMI, SBP, DBP, TG, creatinine, and SUA by multivariate regression analysis (Table 3). Serum uric acid was positively correlated with InsAUC120 (Figure 1, Table 2). The correlation still existed after adjusting possible influencing factors, such as age, BMI, SBP, DBP, HbA1c, TG, and creatinine by multivariate regression analysis (Table 3 ). Serum uric acid showed a negative association with HbAlc in each gender group (male: $r=-0.224, P=0.000$; female: 


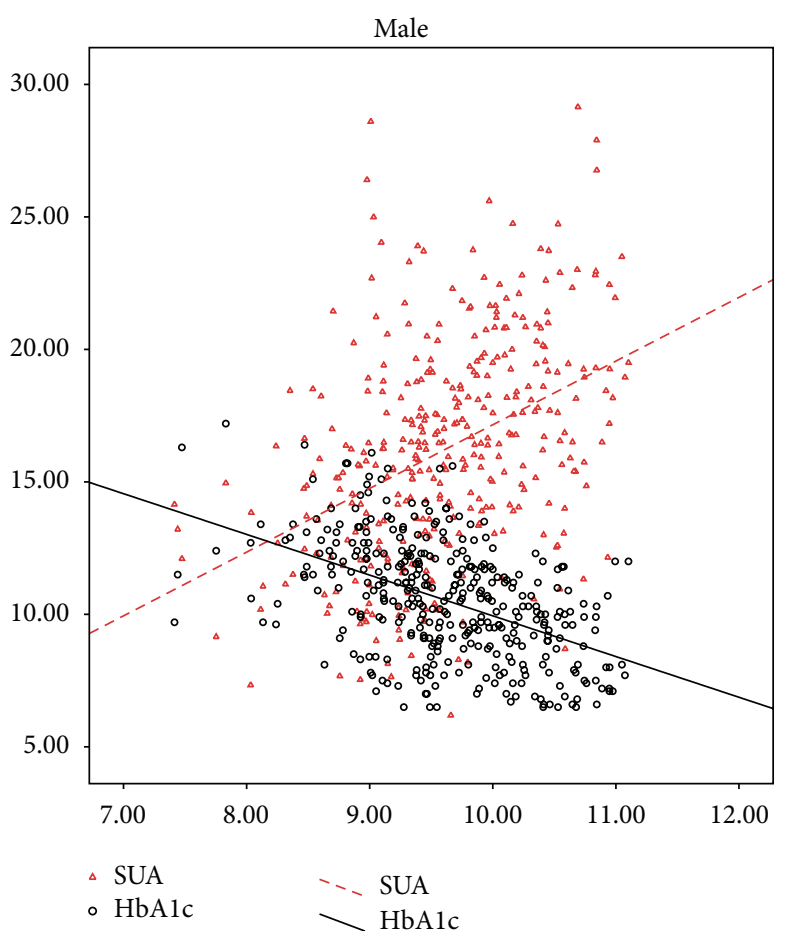

(a)

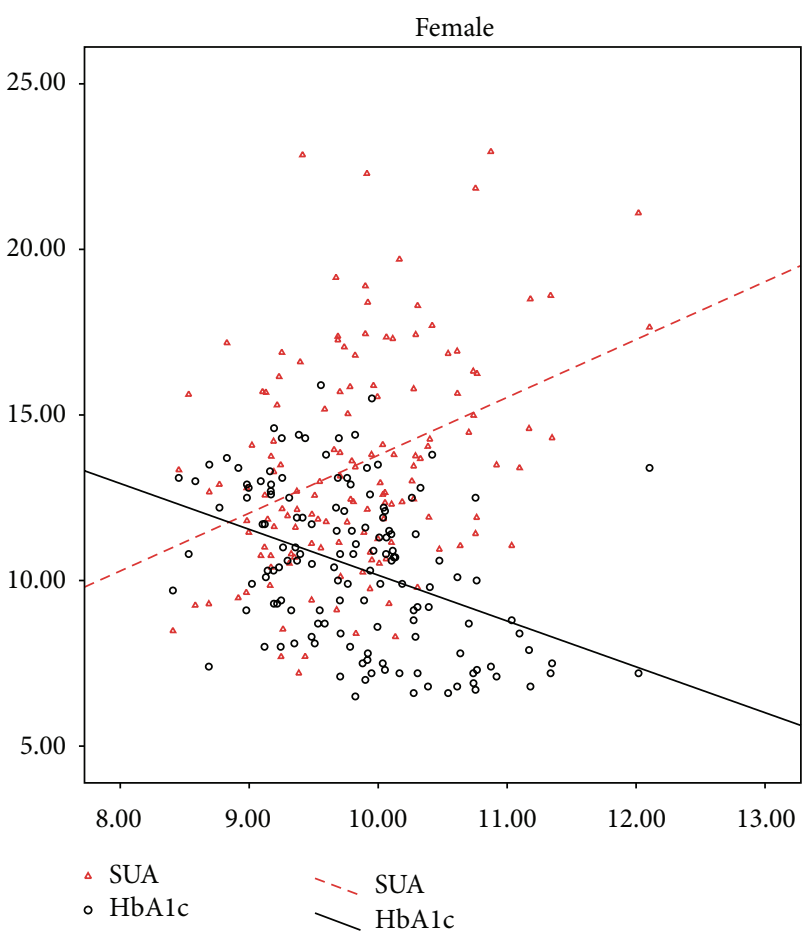

(b)

FIgURE 1: Scatter plots of the correlation between InsAUC120 and SUA as well as HbAlc in different genders. The abscissa is the area under the curve of insulin (InsAUC120). Both uric acid and HbAlc change with the increase in InsAUC120. However, the trends of the two correlation curves are opposite, in either male or female. Serum uric acid is directly correlated with insulin level, and HbAlc is inversely associated with insulin level.

TABLE 2: Correlations between InsAUC120 and SUA as well as HbAlc in different genders.

\begin{tabular}{lcccc}
\hline & \multicolumn{2}{c}{ Male } & \multicolumn{2}{c}{ Female } \\
& $r$ & $P$ & $r$ & $P$ \\
\hline HbA1c & -0.483 & $0.000^{*}$ & -0.456 & $0.000^{*}$ \\
SUA & 0.406 & $0.000^{*}$ & 0.368 & $0.000^{*}$ \\
\hline
\end{tabular}

InsAUC120: the area under the curve of insulin from $0 \mathrm{~min}$ to $120 \mathrm{~min}$ Serum uric acid is positively related to insulin level and $\mathrm{HbAlc}$ is negatively associated with insulin level in both male and female patients. ${ }^{*} P<0.05$ denotes statistical significance.

$r=-0.245, P=0.000)$. When HbAlc increased by one unit, the serum uric acid decreased by 3.868 units in male group and by 6.036 units in female group after adjusting age, BMI, SBP, DBP, TG, and creatinine (Table 3). Interestingly, after adding InsAUC120 to the regression equation, the relationship between uric acid and HbAlc no longer existed (Table 3 ). For both males and females, serum uric acid was inversely correlated with HbAlc levels in high insulin group (male: $r=-0.281, P=0.015$; female: $r=-0.331, P=0.006$ ). The relationship still existed after adjusting possible influencing factors such as age, BMI, SBP, DBP, TG, and creatinine by multivariate regression analysis (Table 4 ). However, no correlation between SUA and HbAlc was present in the low insulin group (male: $r=-0.102, P=0.087$; female: $r=$ $-0.047, P=0.704$; Table 4).

\section{Discussion}

Uric acid is a final product of purine catabolism. It has been confirmed that elevated uric acid levels can increase the risk of metabolic syndrome, atherosclerosis, and chronic kidney disease [12-14]. Over the years, the association between uric acid levels and glucose metabolism has been a hot research topic. A growing number of studies have indicated that there is a "bell" fit between uric acid and glucose concentrations. Uric acid levels tend to decrease after their first increase, along with an increase in blood glucose concentration [15-17]. A number of studies have found that serum uric acid levels are inversely correlated with blood glucose concentrations in type 2 diabetes patients. However, until now, it has been unclear as to why this relationship exists and what factors influence this relationship.

Previous studies have been carried out mainly in patients with preexisting type 2 diabetes. In such patients, the levels of uric acid and blood glucose are easily influenced by alimentary control or medication. For such studies, a single blood sugar reading was taken, which does not represent the total behavior of fluctuating blood sugar levels susceptible to interference/control by medical intervention. In order to explore the relationship between uric acid and blood glucose more accurately, we chose patients with newly diagnosed type 2 diabetes (at time of diagnosis immediately prior to medical intervention) to eliminate the influence of drugs or dietary control. In addition, we used glycosylated hemoglobin 
TABLE 3: Multiple linear regression for SUA, HbAlc, and InsAUC120.

\begin{tabular}{|c|c|c|c|c|c|c|c|c|}
\hline & \multicolumn{4}{|c|}{ Male } & \multicolumn{4}{|c|}{ Female } \\
\hline & $B$ & $\beta$ & $t$ & $P$ & $B$ & $\beta$ & $t$ & $P$ \\
\hline \multicolumn{9}{|c|}{ Model 1: the dependent variable is $\mathrm{HbAlc}$} \\
\hline Age (yr) & 0.007 & 0.038 & 0.662 & 0.508 & 0.061 & 0.265 & 3.198 & $0.002^{*}$ \\
\hline BMI $\left(\mathrm{kg} / \mathrm{m}^{2}\right)$ & 0.028 & 0.045 & 0.752 & 0.452 & 0.133 & 0.190 & 2.302 & $0.023^{*}$ \\
\hline $\mathrm{SBP}(\mathrm{mmHg})$ & -0.003 & -0.027 & -0.474 & 0.636 & 0.009 & 0.060 & 0.692 & 0.490 \\
\hline $\mathrm{DBP}(\mathrm{mmHg})$ & -0.012 & -0.057 & -1.01 & 0.314 & -0.007 & -0.038 & -0.444 & 0.658 \\
\hline TG (mmol/L) & 0.009 & 0.006 & 0.112 & 0.911 & 1.091 & 0.143 & 1.772 & 0.079 \\
\hline $\mathrm{Cr}(\mu \mathrm{mol} / \mathrm{L})$ & -0.014 & -0.082 & -1.524 & 0.128 & -0.027 & -0.114 & -1.429 & 0.156 \\
\hline SUA $(\mu \mathrm{mol} / \mathrm{L})$ & -0.001 & -0.041 & -0.710 & 0.478 & -0.004 & -0.109 & -1.324 & 0.188 \\
\hline InsAUC120 & -1.434 & -0.456 & -7.864 & $0.000^{*}$ & -1.573 & -0.464 & -5.465 & $0.000^{*}$ \\
\hline \multicolumn{9}{|c|}{ Model 2: the dependent variable is SUA } \\
\hline Age (yr) & -1.753 & -0.267 & -5.470 & $0.000^{*}$ & 0.152 & 0.022 & 0.262 & 0.793 \\
\hline BMI $\left(\mathrm{kg} / \mathrm{m}^{2}\right)$ & 5.708 & 0.241 & 5.044 & $0.000^{*}$ & 1.178 & 0.055 & 0.690 & 0.491 \\
\hline $\mathrm{SBP}(\mathrm{mmHg})$ & 0.544 & 0.116 & 2.288 & $0.023^{*}$ & 0.219 & 0.049 & 0.556 & 0.579 \\
\hline $\mathrm{DBP}(\mathrm{mmHg})$ & -0.515 & -0.066 & -1.311 & 0.190 & 0.058 & 0.010 & 0.110 & 0.912 \\
\hline HbAlc (\%) & -3.868 & -0.103 & -2.355 & $0.019^{*}$ & -6.036 & -0.209 & -2.617 & $0.010^{*}$ \\
\hline $\mathrm{TG}(\mathrm{mmol} / \mathrm{L})$ & 4.914 & 0.088 & 1.972 & $0.049^{*}$ & 50.428 & 0.234 & 2.953 & $0.004^{*}$ \\
\hline $\mathrm{Cr}(\mu \mathrm{mol} / \mathrm{L})$ & 2.043 & 0.310 & 6.913 & $0.000^{*}$ & 0.891 & 0.127 & 1.583 & 0.115 \\
\hline \multicolumn{9}{|c|}{ Model 3: the dependent variable is SUA } \\
\hline Age (yr) & -1.694 & -0.257 & -4.945 & $0.000^{*}$ & 0.723 & 0.111 & 1.167 & 0.245 \\
\hline BMI $\left(\mathrm{kg} / \mathrm{m}^{2}\right)$ & 3.136 & 0.135 & 2.419 & $0.016^{*}$ & 0.608 & 0.031 & 0.329 & 0.743 \\
\hline SBP (mmHg) & 0.592 & 0.131 & 2.434 & $0.015^{*}$ & 0.105 & 0.025 & 0.260 & 0.795 \\
\hline DBP (mmHg) & -0.439 & -0.057 & -1.06 & 0.288 & 0.061 & 0.011 & 0.115 & 0.908 \\
\hline HbAlc (\%) & -1.369 & -0.037 & -0.710 & 0.478 & -3.751 & -0.132 & -1.324 & 0.188 \\
\hline $\mathrm{TG}(\mathrm{mmol} / \mathrm{L})$ & 2.839 & 0.051 & 1.049 & 0.295 & 21.665 & 0.100 & 1.117 & 0.266 \\
\hline $\mathrm{Cr}(\mu \mathrm{mol} / \mathrm{L})$ & 1.787 & 0.277 & 5.643 & $0.000^{*}$ & 0.835 & 0.126 & 1.421 & 0.158 \\
\hline InsAUC120 & 26.771 & 0.230 & 3.924 & $0.000^{*}$ & 19.767 & 0.206 & 1.997 & $0.038^{*}$ \\
\hline
\end{tabular}

SBP: systolic pressure, DBP: diastolic pressure, HbAlc: glycosylated hemoglobin, TG: triglycerides, Cr: creatinine, SUA: serum uric acid, and InsAUC120: the area under the curve of insulin from 0 to $120 \mathrm{~min}$. Both uric acid and HbAlc have a regressive relationship with InsAUC120 and some related influencing factors, regardless of gender. There is no regressive relationship between SUA and HbAlc after adjusting InsAUC120. ${ }^{*} P<0.05$ denotes statistical significance.

(HbAlc) as a measure of blood glucose metabolism, not affected by occasional fluctuations in blood sugar. Our study revealed that, among both the male and female patients with newly diagnosed type 2 diabetes, uric acid levels showed a significant upward trend, while the HbAlc levels were significantly lower and correlated with an increase in InsAUC120 levels. This data suggested that a change in insulin level may lead to a degree of correlation between uric acid and $\mathrm{HbAlc}$. Subsequently, we found that the serum uric acid levels were inversely correlated with HbAlc levels, regardless of patient gender. However, the correlation between uric acid and $\mathrm{HbAlc}$ disappeared after adjusting InsAUC120 through multiple linear regression analysis. This further indicated that the correlation between uric acid and HbAlc may be affected by InsAUC120. Therefore, the correlation between uric acid and $\mathrm{HbAlc}$ was analyzed by stratified analysis according to insulin level. Only in the case of high insulin levels, we found that serum uric acid was inversely correlated with HbAlc. There was no association between uric acid and HbAlc in patients with low insulin levels. Therefore, the correlation between uric acid and $\mathrm{HbAlc}$ most likely relies on insulin levels. Modan et al. [10] showed that there were differences in uric acid concentration among the general population, those with impaired glucose tolerance, and newly diagnosed type 2 diabetes patients, only when hyperinsulinemia existed. However, if patients had normal insulin levels, there were no differences in serum uric acid levels, regardless of blood glucose levels. Therefore, the findings of Modan et al. agree with our results. The reasons for the above situation may be due to the effect of insulin on the metabolism of uric acid and glucose. Hyperinsulinemia could increase the activation of the hexose phosphate shunt, which would promote the biosynthesis and transformation of purine, thus increasing the rate of uricogenesis [18]. At the same time, insulin may increase reabsorption of uric acid from the kidneys by stimulating the urate anion transporter on the border membrane in the proximal tubular brush [19], the end result of which is an increase in the concentration of serum uric acid. High insulin 
TABLE 4: Multiple linear regression for SUA and HbAlc in patients with high and low insulin levels.

\begin{tabular}{|c|c|c|c|c|c|c|c|c|}
\hline & \multicolumn{4}{|c|}{ Male } & \multicolumn{4}{|c|}{ Female } \\
\hline & $B$ & $\beta$ & $t$ & $P$ & $B$ & $\beta$ & $t$ & $P$ \\
\hline \multicolumn{9}{|c|}{ High insulin levels: the dependent variable is SUA } \\
\hline Age (yr) & -2.062 & -0.355 & -4.346 & $0.000^{*}$ & 1.224 & 0.181 & 1.324 & 0.191 \\
\hline BMI $\left(\mathrm{kg} / \mathrm{m}^{2}\right)$ & 4.480 & 0.200 & 2.644 & $0.009^{*}$ & 3.382 & 0.149 & 1.207 & 0.232 \\
\hline $\mathrm{SBP}(\mathrm{mmHg})$ & 0.156 & 0.033 & 0.383 & 0.702 & 0.714 & 0.170 & 0.976 & 0.333 \\
\hline DBP (mmHg) & 0.164 & 0.023 & 0.263 & 0.793 & -0.601 & -0.083 & -0.474 & 0.637 \\
\hline HbAlc (\%) & -4.923 & -0.111 & -1.582 & $0.016^{*}$ & -9.995 & -0.329 & -2.450 & $0.007^{*}$ \\
\hline $\mathrm{TG}(\mathrm{mmol} / \mathrm{L})$ & 5.363 & 0.099 & 1.382 & 0.169 & 4.654 & 0.049 & 0.382 & 0.704 \\
\hline $\mathrm{Cr}(\mu \mathrm{mol} / \mathrm{L})$ & 1.670 & 0.244 & 3.262 & $0.001^{*}$ & 0.124 & 0.018 & 0.136 & 0.892 \\
\hline \multicolumn{9}{|c|}{ Low insulin levels: the dependent variable is SUA } \\
\hline Age (yr) & -0.973 & -0.143 & -1.858 & 0.065 & 0.577 & 0.097 & 0.631 & 0.531 \\
\hline BMI $\left(\mathrm{kg} / \mathrm{m}^{2}\right)$ & 3.017 & 0.118 & 1.561 & 0.121 & -0.138 & -0.008 & -0.055 & 0.956 \\
\hline $\mathrm{SBP}(\mathrm{mmHg})$ & 0.792 & 0.201 & 2.520 & 0.013 & -0.338 & -0.086 & -0.585 & 0.561 \\
\hline $\mathrm{DBP}(\mathrm{mmHg})$ & -1.276 & -0.166 & -2.152 & 0.033 & 0.345 & 0.078 & 0.587 & 0.560 \\
\hline HbAlc (\%) & -2.850 & -0.062 & -1.202 & 0.131 & 0.230 & 0.008 & 0.056 & 0.956 \\
\hline $\mathrm{TG}(\mathrm{mmol} / \mathrm{L})$ & 0.372 & 0.007 & 0.096 & 0.924 & 12.483 & 0.156 & 1.108 & 0.273 \\
\hline $\mathrm{Cr}(\mu \mathrm{mol} / \mathrm{L})$ & 1.974 & 0.352 & 4.782 & $0.000^{*}$ & 1.400 & 0.226 & 1.723 & 0.090 \\
\hline
\end{tabular}

Serum uric acid has an independent relationship with HbAlc through multiple stepwise regression analysis in patients with hyperinsulinemia, while there is no association between SUA and HbAlc in patients with hypoinsulinemia. ${ }^{*} P<0.05$ denotes statistical significance.

levels naturally lead to lower blood glucose concentrations. Therefore, insulin may control the concentration of uric acid and blood glucose at the same time, explaining the inverse correlation between uric acid and blood glucose when blood insulin levels are high.

In conclusion, our study confirmed that there is an inverse correlation between uric acid and $\mathrm{HbAlc}$, which is dependent on hyperinsulinemia in patients with newly diagnosed type 2 diabetes. High insulin levels may be an important factor affecting the correlation between the uric acid and $\mathrm{HbAlc}$. Out results suggest that uric acid might serve as a biomarker of blood glucose, but only under conditions of hyperinsulinemia.

\section{Competing Interests}

No competing interests exist regarding the publication of this paper.

\section{Authors' Contributions}

Yuliang Cui and Hemei Bu performed the experiments and wrote the paper together; Xianghua Ma conceived and designed the experiments and supported fund; Sha Zhao participated in the design of the study and performed the statistical analysis; Xiaona Li participated in data collection; Shan Lu participated in data analysis. All authors read and approved the final paper. Dr. Yuliang Cui and Dr. Hemei $\mathrm{Bu}$ contributed equally to this paper and share the first authorship.

\section{Acknowledgments}

The authors would like to thank the Duoease Scientific Service Center for excellent language editing service. Thanks are due to Xiaoping Zhou (Director of Information Center, W\&C Branch Hospital of Jiangsu Province Hospital) and Zhihang Peng (Professor of School of Public Health, Nanjing Medical University), the statisticians who performed the statistical analysis.

\section{References}

[1] P. P. Singh, F. Mahadi, A. Roy, and P. Sharma, "Reactive oxygen species, reactive nitrogen species and antioxidants in etiopathogenesis of diabetes mellitus type-2," Indian Journal of Clinical Biochemistry, vol. 24, no. 4, pp. 324-342, 2009.

[2] Q. Lv, X.-F. Meng, F.-F. He et al., "High serum uric acid and increased risk of type 2 diabetes: a systemic review and metaanalysis of prospective cohort studies," PLoS ONE, vol. 8, no. 2, Article ID e56864, 2013.

[3] B. Xue, J. B. Tan, F. Ning et al., "Association between serum uric acid and prevalence of type 2 diabetes diagnosed using HbAlc criteria among Chinese adults in Qingdao, China," Biomedical and Environmental Sciences, vol. 28, no. 12, pp. 884-893, 2015.

[4] Q. Qiu, Y. Gong, X. Liu et al., "Serum uric acid and impaired glucose tolerance: The Cardiometabolic Risk in Chinese (CRC) Study," Cell Biochemistry and Biophysics, vol. 73, no. 1, pp. 155$162,2015$.

[5] I. Sluijs, J. W. J. Beulens, D. L. van der A, A. M. W. Spijkerman, M. B. Schulze, and Y. T. Van Der Schouw, "Plasma uric acid is associated with increased risk of type 2 diabetes independent of diet and metabolic risk factors," Journal of Nutrition, vol. 143, no. 1, pp. 80-85, 2013.

[6] J. B. Herman, J. H. Medalie, and U. Goldbourt, "Diabetes, prediabetes and uricaemia," Diabetologia, vol. 12, no. 1, pp. 47$52,1976$.

[7] J. Tuomilehto, P. Zimmet, E. Wolf, R. Taylor, P. Ram, and H. King, "Plasma uric acid level and its association with diabetes mellitus and some biologic parameters in a biracial population 
of Fiji," American Journal of Epidemiology, vol. 127, no. 2, pp. 321336, 1988.

[8] A. Gill, S. Kukreja, N. Malhotra, and N. Chhabra, "Correlation of the serum insulin and the serum uric acid levels with the glycated haemoglobin levels in the patients of type 2 diabetes mellitus," Journal of Clinical and Diagnostic Research, vol. 7, no. 7, pp. 1295-1297, 2013.

[9] J. A. Robles-Cervantes, M. G. Ramos-Zavala, M. GonzálezOrtiz et al., "Relationship between serum concentration of uric acid and insulin secretion among adults with type 2 diabetes mellitus," International Journal of Endocrinology, vol. 2011, Article ID 107904, 4 pages, 2011.

[10] M. Modan, H. Halkin, A. Karasik, and A. Lusky, "Elevated serum uric acid-a facet of hyperinsulinaemia," Diabetologia, vol. 30, no. 9, pp. 713-718, 1987.

[11] M. M. Tai, "A mathematical model for the determination of total area under glucose tolerance and other metabolic curves," Diabetes Care, vol. 17, no. 2, pp. 152-154, 1994.

[12] D. Yadav, E. S. Lee, H. M. Kim et al., "Prospective study of serum uric acid levels and incident metabolic syndrome in a Korean rural cohort," Atherosclerosis, vol. 241, no. 1, pp. 271-277, 2015.

[13] M. E. Kleber, G. Delgado, T. B. Grammer et al., "Uric acid and cardiovascular events: a Mendelian randomization study," Journal of the American Society of Nephrology, vol. 26, no. 11, pp. 2831-2838, 2015.

[14] T. Toyama, K. Furuichi, M. Shimizu et al., "Relationship between serum uric acid levels and chronic kidney disease in a Japanese cohort with normal or mildly reduced kidney function," PLoS ONE, vol. 10, no. 9, Article ID e0137449, 2015.

[15] D. G. Cook, A. G. Shaper, D. S. Thelle, and T. P. Whitehead, "Serum uric acid, serum glucose and diabetes: relationships in a population study," Postgraduate Medical Journal, vol. 62, no. 733, pp. 1001-1006, 1986.

[16] T. P. Whitehead, I. Jungner, D. Robinson, W. Kolar, A. Pearl, and A. Hale, "Serum urate, serum glucose and diabetes," Annals of Clinical Biochemistry, vol. 29, no. 2, pp. 159-161, 1992.

[17] H. K. Choi and E. S. Ford, "Haemoglobin Alc, fasting glucose, serum C-peptide and insulin resistance in relation to serum uric acid levels-The Third National Health and Nutrition Examination Survey," Rheumatology, vol. 47, no. 5, pp. 713-717, 2008.

[18] I. H. Fox, "Metabolic basis for disorders of purine nucleotide degradation," Metabolism, vol. 30, no. 6, pp. 616-634, 1981.

[19] S. Tsunoda, K. Kamide, J. Minami, and Y. Kawano, "Decreases in serum uric acid by amelioration of insulin resistance in overweight hypertensive patients: effect of a low-energy diet and an insulin-sensitizing agent," American Journal of Hypertension, vol. 15, no. 8, pp. 697-701, 2002. 


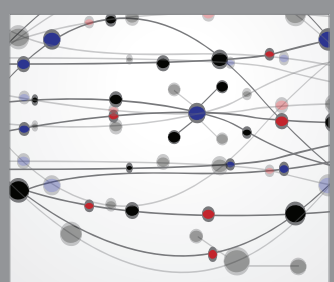

The Scientific World Journal
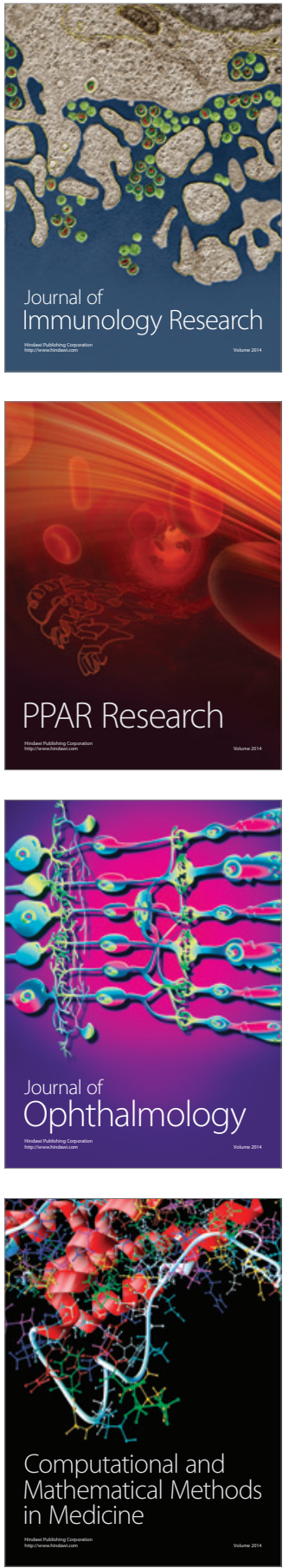

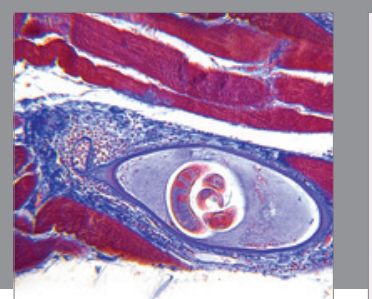

Gastroenterology Research and Practice

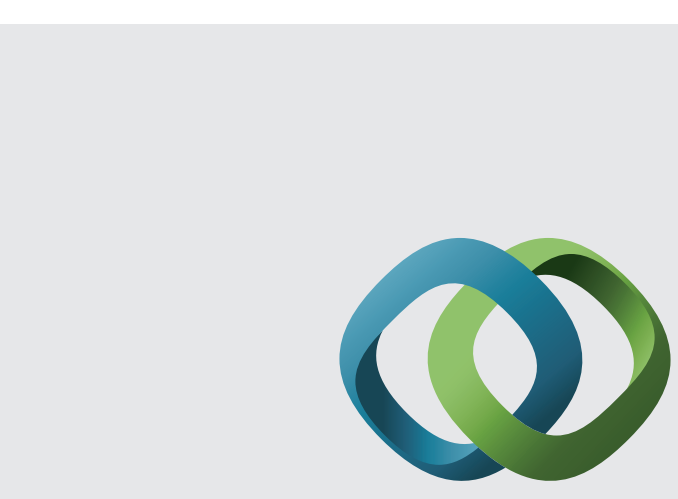

\section{Hindawi}

Submit your manuscripts at

http://www.hindawi.com
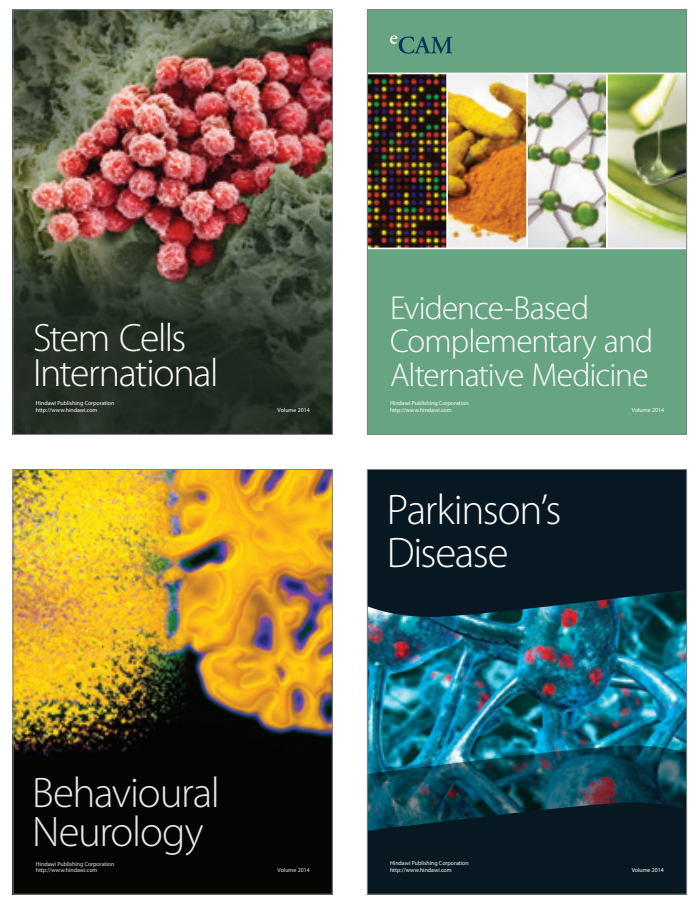
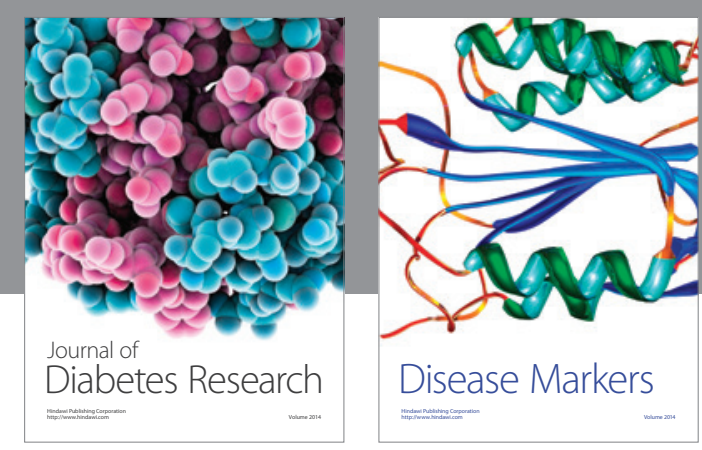

Disease Markers
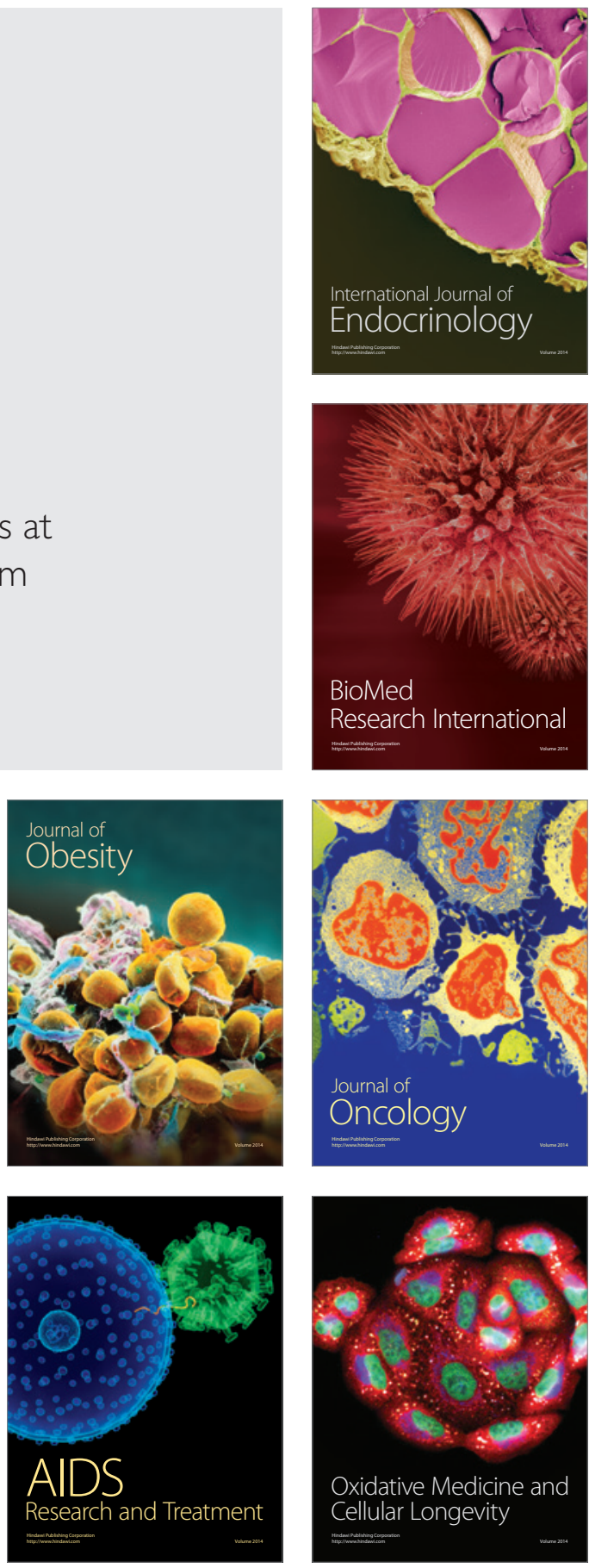